\title{
ORIGINAL ARTICLE \\ Combined detrusor-trigone BTX-A injections for urinary incontinence secondary to neurogenic detrusor overactivity
}

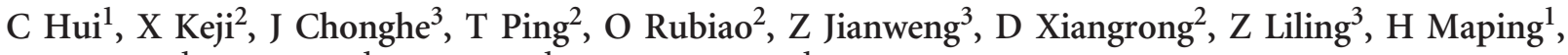 \\ L Qingqing $^{1}$, L Qiuling ${ }^{1}, \mathrm{H}$ Jiebing ${ }^{1}$ and $\mathrm{H}_{\text {Tanghai }}{ }^{1}$
}

\begin{abstract}
Objectives: The objective of this study was to evaluate the effect and safety of trigonal injection of botulinum toxin A (BTX-A) for patients with neurological detrusor overactivity (NDO) with incontinence.

Methods: A prospective, multicenter, single-blind and randomized controlled trial was conducted between June 2011 and June 2014. Spinal cord injury patients with urinary incontinence secondary to NDO overactivity were recruited. At a 1:1 ratio, patients randomly received $200 \mathrm{U}$ BTX-A intradetrusor injections excluding the trigone (the control group) or $160 \mathrm{U}$ intradetrusor and $40 \mathrm{U}$ intratrigonal injections (the experimental group). Patients were evaluated at baseline and at 4 and 12 weeks after injection. The efficacy and safety outcomes included Incontinence-Specific-Quality-of-Life Instrument (I-QoL), voiding volume, urinary incontinence episodes, complete dryness, maximum detrusor pressure $\left(P_{\text {detmax }}\right)$ and volume at first involuntary detrusor contraction $\left(V_{\text {FIDC }}\right)$. Vesicoureteral reflux $(V U R)$ and other adverse events were recorded.
\end{abstract}

Results: Ninety-six patients were recruited and 91 of them completed the trial. Among the 91 patients, 47 were randomized to the experimental group and 44 to the control group. There were no significant differences in baseline evaluation items (gender, age, duration of spinal cord injury, level of neurological injury, AIS (the American Social Injury Association) scores) between the two groups. At 12 weeks, the improvement was significantly better in the experimental group compared with that in the control group for I-QoL (26.01 vs $18.75, P=0.01$ ), mean urinary incontinence episodes $(-5.22$ vs -4.68 per day, $P=0.01)$, complete dryness ( 13 vs 5 , $P=0.03)$, mean voiding volume $(159.72$ vs $139.07 \mathrm{ml}, P=0.02), P_{\operatorname{detmax}}\left(-33.34\right.$ vs $\left.-28.02 \mathrm{cmH} \mathrm{H}_{2} \mathrm{O}, P=0.04\right)$ and $\mathrm{VFIDC}$ (106.81 vs $97.86 \mathrm{ml}, P=0.02)$, duration of first detrusor contraction $(-41.54 \mathrm{vs}-18.65 \mathrm{~s}, P=0.03$ ) and the number of patients with detrusor contraction ( -20 vs $-9, P=0.02$ ). In both the groups, no patients developed VUR.

Conclusions: BTX-A intradetrusor and intratrigonal injections are more effective compared with those excluding the trigone for patients with NDO with incontinence. Intratrigonal injections do not induce VUR.

Spinal Cord (2016) 54, 46-50; doi:10.1038/sc.2015.143; published online 11 August 2015

\section{INTRODUCTION}

Detrusor overactivity (DO) is characterized by spontaneous or provoked involuntary detrusor contractions during storage phase in urodynamic investigation. ${ }^{1,2}$ Neurogenic DO (NDO) is DO caused by various neurogenic diseases such as brain tumors, dementia, multiple sclerosis, Parkinson's disease, stroke and spinal cord injury (SCI). ${ }^{3}$ NDO can cause a variety of long-term complications such as urinary incontinence, stones, hydronephrosis, recurrent urinary tract infection and VUR; the most dangerous being damage of renal function. These complications may markedly impact the quality of life of people with SCI, including limiting their behavior, causing social embarrassment and possibly threatening their life. ${ }^{4}$

Botulinum toxin A (Botox; Allergan) is an acetylcholine release inhibitor and a neuromuscular blocking agent indicated by the beneficial treatment effect on NDO patients who have an inadequate response to or are intolerant to anticholinergic medication according to both clinical and urodynamic test, such as improvement percentage of Incontinence-Specific-Quality-of-Life Instrument (I-QoL), reduction of urinary incontinence episodes and lower detrusor pressure and so on. ${ }^{5,6}$
In the past 10 years, intradetrusor injection of BTX-A was performed while avoiding the trigone to prevent VUR. ${ }^{7}$ However, several studies reported that there are abundant sensory nerve fibers in bladder trigone, and its smooth muscles are sensitive to small pressure changes. ${ }^{8,9}$ Based on these findings, combined detrusortrigone BTX-A injections may desensitize the bladder and thereby help to reduce bladder uninhibited contraction and dyssynergia.

To our knowledge, several studies reported satisfactory clinical results about combined detrusor-trigone BTX-A injections. ${ }^{10-15}$ However, most of these studies were small and single-center experience. Therefore, the objective of this prospective, multicenter, single-blind and randomized controlled trial was to evaluate the efficacy and safety of combined detrusor-trigone BTX-A injections for NDO with urinary incontinence.

\section{MATERIALS AND METHODS}

Study population

This trial was conducted in three different institutions from 18 June 2011 to 23 June 2014. Eligible SCI in-patients for the study were recruited. Inclusion criteria were: (1) at least 18 years old with various neurogenic disorders;

${ }^{1}$ Department of Urology, Guangdong Provincial Work Injury Rehabilitation Hospital, Jinan University, Guangzhou, China; ${ }^{2}$ Department of Urology, Guangzhou First Municipal People's Hospital, Guangzhou, China and ${ }^{3}$ Department of Urology, Qingyan City People's Hospital, Jinan University, Guangdong, China

Correspondence: Dr C Hui, Department of Urology, Guangdong Provincial Work Injury Rehabilitation Hospital, Jinan University, Guangzhou 510440, China.

E-mail: doc.chenhui @163.com

Received 15 April 2015; revised 17 June 2015; accepted 28 June 2015; published online 11 August 2015 
(2) urodynamic DO with urinary incontinence; (3) an inadequate response or intolerance to oral anticholinergic drugs; (4) participants or their caregiver could perform clean intermittent catheterization (CIC). Exclusion criteria were: (1) an allergy to BTX-A; (2) women were pregnant, lactating or planning to become pregnant during the course of the trial; (3) acute urinary tract infection. All patients were given a thorough explanation of both modes of treatment and provided written informed consent before injection. A urology resident not participating in the operations assigned patients to treatment based on a randomization schedule from a random-number table balanced in blocks of 6 . The study was approved by the ethics committees of the three participating hospitals.

\section{Study design}

The study was a prospective, multicenter, single-blind and randomized comparison of combined detrusor-trigone BTX-A (Botox; commercial lot 2024; Allergan; $100 \mathrm{U} \mathrm{ml}^{-1}$ ) injections with detrusor BTX-A injections (Figure 1). At a 1:1 ratio, patients were randomly assigned to an experimental group, who received $160 \mathrm{U}$ intradetrusor plus $40 \mathrm{U}$ intratrigonal injections, or to a control group, who received $200 \mathrm{U}$ BTX-A intradetrusor injections excluding the trigone.

\section{Study outcomes}

The primary end-point outcomes were the changes in the videourodynamic test evaluated at baseline, and at 12 weeks after injection: (1) incidence of VUR; (2) maximum detrusor pressure during first involuntary detrusor contraction $\left(P_{\text {detmaxIDC }}\right)$ during filling storage; (3) volume at first involuntary detrusor contraction $\left(V_{\mathrm{FIDC}}\right)$; (4) duration of first DO; and (5) incidence of DO.

Secondary end-point outcomes assessed at baseline and during weeks 4 and 12 after injections were I-QoL, ${ }^{16}$ voiding volume, urinary incontinence episodes between CICs per $24 \mathrm{~h}$ and complete dryness. The I-QoL contains 22 items evaluating problems related to incontinence. Items are scored on a 5-point scale with values ranging from 1 (extreme) to 5 (not at all). Scores were then converted to a scale ranging from 0 (worst I-QoL) to 100 (best I-QoL). Voiding volume is defined as voided volume by CIC plus spontaneous voids. Complete dryness is defined as $<1$ incontinence episode per $24 \mathrm{~h}$. All these outcomes were determined from seven consecutive days of the patient's bladder diary. The related adverse events were recorded throughout the study.

\section{Injections}

Injections were performed with no anesthesia or under epidural anesthesia in the operating room with a $21 \mathrm{~F}$ rigid cystoscope (Ackermann, Schaffhausen, Switzerland). The bladder was instilled with $100-150 \mathrm{ml}$ sterile saline to achieve adequate visualization so as to avoiding the blood vessels during injections. A 23-gauge needle (Cook Urological Incorporated, Bloomington, IN, USA) was inserted $\sim 2 \mathrm{~mm}$ into the detrusor. The $200 \mathrm{U}$ Botox vials (100 U each) were reconstituted in a total of $30 \mathrm{ml}$ sterile saline $\left(6.7 \mathrm{U} \mathrm{ml}^{-1}\right)$. A total of 30 injections of $1 \mathrm{ml}$ each were administered, evenly distributed about $1 \mathrm{~cm}$ apart across the bladder wall. Patients in the experimental group had six 1-ml (total $40 \mathrm{U}$ ) injections into the bladder trigone sparing a $5 \mathrm{~mm}$ distance to the vicinity of the ureteral orifices and the bladder neck, and $241-\mathrm{ml}$ injections (total $160 \mathrm{U}$ ) into the bladder wall (Figure 2a). Patients in the control group had 1-ml injections at 30 sites into the bladder wall, avoiding the trigone. Both procedures were performed by a single senior urologist with extensive experience in BTX-A injections (Figure 2b). In both procedures, a 16 Foley catheter had been inserted for 3-5 days. Oral prophylactic antibiotics (except aminoglycosides) were administered on the day of treatment.

\section{Statistical analysis}

Student's $t$-test was used for comparison of related variables of both groups and results are presented as means \pm s.d. The $\chi^{2}$ test was used for categorical data. A $P$-value $\leqslant 0.05$ was considered statistically significant. Statistical analyses were performed with SPSS 13.0 software (SPSS Inc., Chicago, IL, USA).

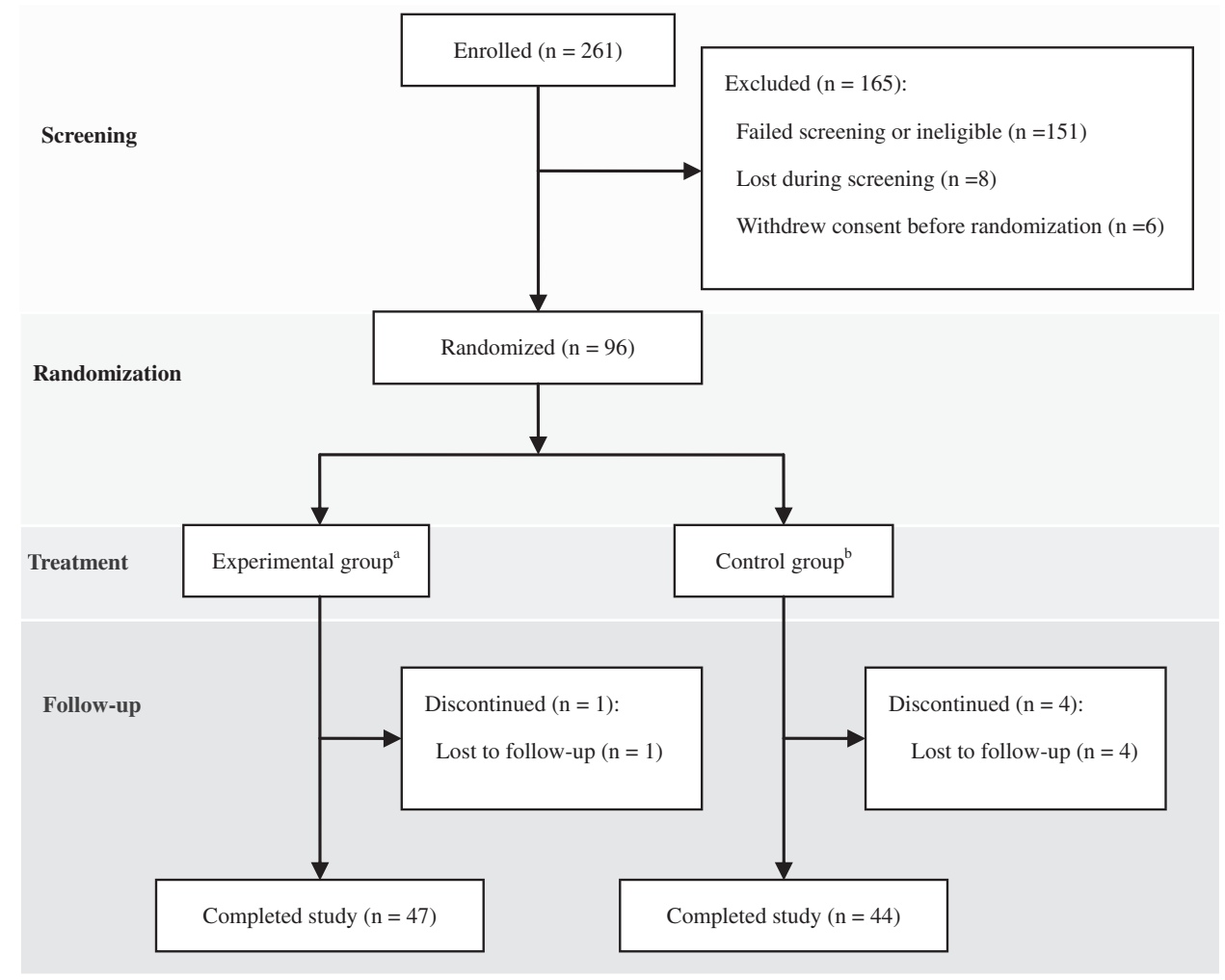

${ }^{\mathrm{a}} 160 \mathrm{U}$ BTX-A intradetrusor + $40 \mathrm{U}$ BTX-A intratrigonal injections; ${ }^{\mathrm{b}} 200 \mathrm{U}$ BTX-A intradetrusor injections

Figure 1 Flow chart shows screening, randomization, treatment and follow-up of the study. A full color version of this figure is available at the Spinal Cord journal online. 


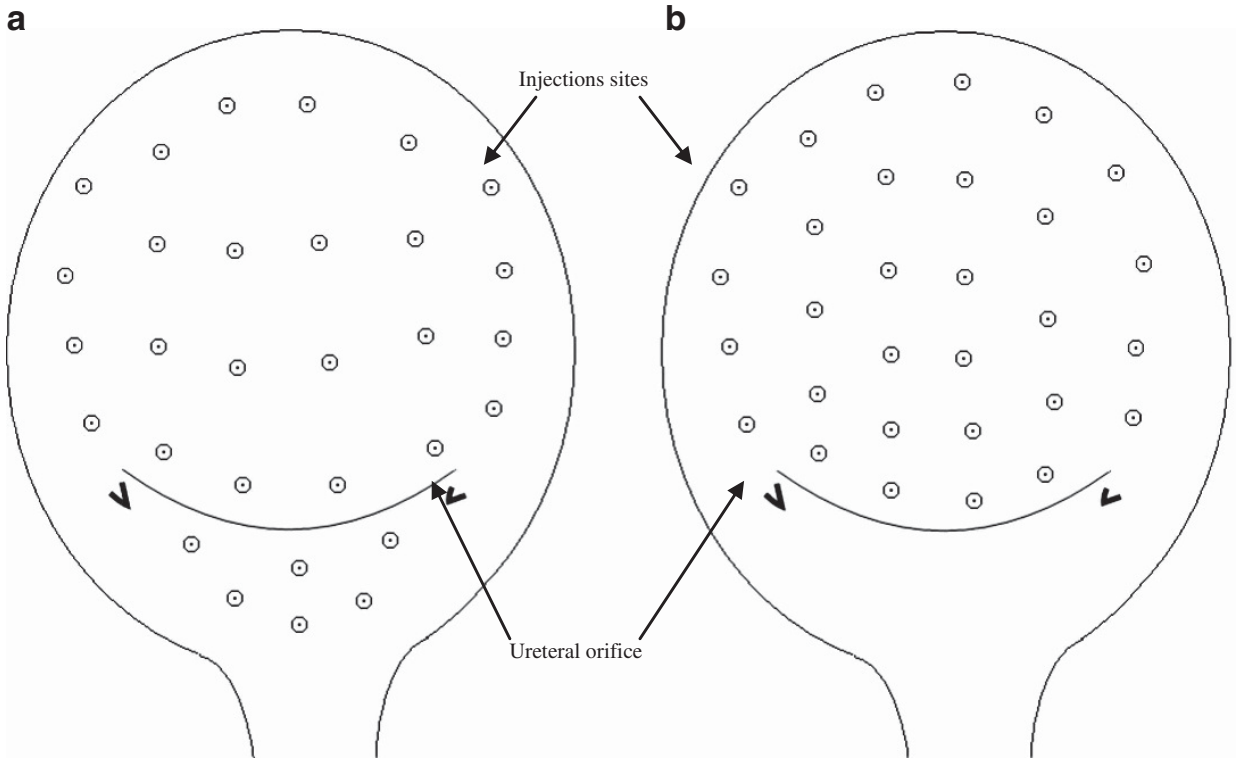

Figure 2 Location of BTX-A injection sites. (a) The $160 \mathrm{U}$ intradetrusor plus $40 \mathrm{U}$ intratrigonal and (b) $200 \mathrm{U}$ intradetrusor injections.

Table 1 Baseline characteristics of the participants

\begin{tabular}{|c|c|c|c|}
\hline Characteristic & $\begin{array}{l}\text { Experimental group } \\
\qquad(\mathrm{n}=47)\end{array}$ & $\begin{array}{l}\text { Control group } \\
\qquad(\mathrm{n}=44)\end{array}$ & P-value \\
\hline Age (years), mean (s.d.) & $29.83(11.77)$ & $28.46(10.36)$ & 0.56 \\
\hline Gender, men, $n(\%)$ & $28(59.57)$ & $23(52.27)$ & 0.48 \\
\hline Weight (kg), mean (s.d.) & $67.16(19.25)$ & $65.93(20.62)$ & 0.77 \\
\hline Duration of spinal cord injury (months), mean (s.d.) & $20.04 \pm 6.56$ & $19.43 \pm 5.48$ & 0.63 \\
\hline Episodes $^{a}$ of urinary incontinence $(n / d)$, mean (s.d.) & $7.38 \pm 2.64$ & $7.34 \pm 2.31$ & 0.94 \\
\hline Level of SCl injury, C6-C8/ T1-T12/ L1-L5, n & $6 / 28 / 13$ & $9 / 26 / 9$ & 0.52 \\
\hline AIS grade, $A / B / C, n$ & $27 / 12 / 8$ & 29/10/5 & 0.66 \\
\hline Prior anticholinergic drugs use, $n(\%)$ & $43(91.49)$ & $41(95.35)$ & 0.76 \\
\hline Prior $\mathrm{CIC}$ use, $n(\%)$ & $45(100)$ & $42(100)$ & 0.95 \\
\hline
\end{tabular}

Abbreviations: AIS, the American Social Injury Association; CIC, clean intermittent catheterization; SCI, spinal cord injury.

aThe variable was assessed from the patients' 7-day bladder diary.

\section{RESULTS}

Of the 261 participants screened at three participating hospital, 165 patients were excluded from the study, consisting of 151 who failed to screening because of SCI patients with age below 18 years old $(n=27)$, detrusor underactivity or acontractility $(n=78)$, acute urinary tract infection or epididymitis $(n=28)$, an allergy to BTX-A $(n=2)$, compromised respiratory function $(n=16)$; another eight who lost during screening $(n=8)$; and six who withdrew consent before randomization $(n=6)$. Among 96 who underwent randomization, 5 patients were lost to follow-up at week 4 because of moving abroad $(n=1)$ or losing contact $(n=4)$. Therefore, a total of 91 SCI patients ( 47 assigned to the experimental group and 44 assigned to the control group) completed 12 weeks of follow-up and data were available and analyzed (Figure 1). At baseline, there were no significant differences between groups with respect to any demographic or baseline characteristics (Table 1).

\section{Efficacy}

The primary end-point outcomes. No patient developed unilateral or bilateral VUR at week 12. Patients with $160 \mathrm{U}$ BTX-A intradetrusor plus $40 \mathrm{U}$ BTX-A intratrigonal injections had statistically greater improvement compared with those in the control group for $P_{\text {detmaxIDC }}$ $\left(-33.34\right.$ vs $\left.-28.02 \mathrm{cmH}_{2} \mathrm{O}, P=0.04\right)$, VFIDC $(106.81$ vs $97.86 \mathrm{ml}$, $P=0.02)$, duration of first detrusor contraction $(-41.54 \mathrm{vs}-18.65 \mathrm{~s}$, $P=0.03)$ and the number of patients with detrusor contraction $(-20$ vs $-9, P=0.02)$ at week 12 (Table 2$)$.

Secondary end-point outcomes. Table 3 shows that significant changes were already present in both groups by week 4 for mean dairy UI episodes $(-4.74$ vs -4.25 per day, $P=0.03)$, complete dryness (13 vs $5, P=0.03)$, mean voiding volume $(159.39$ vs $140.16 \mathrm{ml}$, $P=0.04)$ and I-QoL $(24.97$ vs $19.59, P=0.02)$, respectively. Furthermore, patients in the experimental group still yielded significant improvements in mean urinary incontinence episodes ( -5.22 vs -4.68 per day, $P=0.01)$, complete dryness (13 vs 5 , $P=0.03)$, mean voiding volume (159.72 vs $139.07 \mathrm{ml}, P=0.02)$ and I-QoL (26.01 vs $18.75, P=0.01)$ compared with those in the control group at week 12 .

Safety and tolerability. During the first week after injection, we observed three patients (two in the experimental group, one in the 
Table 2 Mean baseline and change from baseline in primary outcomes: VUR, $P_{\text {detmax }}, V_{\text {FIDC, }}$, duration of first detrusor contraction and patients with detrusor contraction

\begin{tabular}{ccc}
\hline Outcome & Experimental group & Control group \\
$(\mathrm{n}=47)$ & $(\mathrm{n}=44)$ & P-value
\end{tabular}

Incidence of VUR, $\mathrm{n}$ (\%)

$\begin{array}{llll}\text { Baseline } & 0 & 0 & \text { NS } \\ \text { Week } 12 & 0 & 0 & \text { NS }\end{array}$

Pdetmaxa $\left(\mathrm{CmH}_{2} \mathrm{O}\right)$, mean (s.d.)

Baseline $\quad 68.38 \pm 17.96$

Week 12

$68.94 \pm 16.01$

$-28.02 \pm 15.18$

0.87

0.04

$\operatorname{VFIDC}(m l)$, mean (s.d.)

Baseline

$165.55 \pm 41.96$

$170.98 \pm 36.48$

Week 12

$106.81 \pm 56.15$

$97.86 \pm 42.79$

0.51

0.02

Duration of first detrusor contraction ${ }^{a}$ (s), mean (s.d.)

$\begin{array}{lcc}\text { Baseline } & 87.22 \pm 67.43 & 84.61 \pm 69.87 \\ \text { Week } 12 & -41.54 \pm 38.27 & -18.65 \pm 49.13\end{array}$

Number of patients with involuntary detrusor contraction, $\mathrm{n}(\%)$

$\begin{array}{lcc}\text { Baseline } & 47(100) & 44(100) \\ \text { Week } 12 & -20(-42.55) & -9(-20.45)\end{array}$

Abbreviations: NS, no significance; $P_{\text {detmax }}$, maximum detrusor pressure during first involuntary detrusor contraction; VFIDC, volume at first involuntary detrusor contraction; VUR, vesicoureteral reflux.

aOnly includes patients who had an DO.

control group) with mild transient hematuria. Two patients in the control group reported bladder discomfort at week 1 . All patients did not require any medication or surgical intervention.

\section{DISCUSSION}

Since the introduction of botulinum toxin for the treatment of NDO, the majority of urologists have avoided trigone infiltration to prevent VUR. ${ }^{5,7}$ Our study demonstrates that it does not induce vesicoureteral reflux during the 12-week follow-up after injection. In 2007, Karsenty et al. ${ }^{10}$ firstly reported that in the 11 female patients with nonneurogenic overactive bladder who received $100 \mathrm{U}$ botox injection (five sites) into trigone, there was no induced VUR and the patient who had VUR at baseline showed no change in VUR grade at the 6-week videourodynamic test. In 2008, Citeri et al. ${ }^{11}$ retrieved 240 patients with NDO who were treated with $250 \mathrm{U}$ Dysport into the trigone, no VUR was recorded. In 2010, Pinto et al. ${ }^{12}$ and Abdel-Meguid $^{13}$ reported that 26 patients with bladder pain syndrome/interstitial cystitis and nine patients with NDO who received $100 \mathrm{U}$ botox injections into 10 trigonal sites, respectively, and no cases of VUR occurred in both studies. In 2011, Kuo ${ }^{14}$ and Manecksha et al. ${ }^{15}$ also reported no incidences of VUR in 68 patients and 11 patients with idiopathic DO after injections of $100 \mathrm{U}$ botox injections into the bladder trigone.

The primary aim in the treatment of NDO is to ensure that the detrusor pressure remains within safe limits during both the filling phase and the voiding phase for protection of the upper urinary tract. ${ }^{17}$ The present trial reports significant improvements in these parameters were evident with the $200 \mathrm{U}$ dose of BTX-A injection with or without trigone injection. In this trial, although the follow-up period was relatively short, BTX-A intradetrusor and intratrigonal injections were superior to those excluding the trigone with respect to
Table 3 Mean baseline and change from baseline in secondary outcomes: I-QoL, voiding volume ${ }^{\mathrm{a}}$, urinary incontinence episodes ${ }^{\mathrm{a}}$ and patients with complete dryness ${ }^{a}$

\begin{tabular}{|c|c|c|c|}
\hline Outcome & $\begin{array}{l}\text { Experimental group } \\
\qquad(n=47)\end{array}$ & $\begin{array}{l}\text { Control group } \\
\qquad(n=44)\end{array}$ & P-value \\
\hline \multicolumn{4}{|c|}{ Urinary incontinence episodes (n per day), mean (s.d.) } \\
\hline Baseline & $7.38 \pm 2.64$ & $7.34 \pm 2.31$ & 0.94 \\
\hline Week 4 & $-4.74 \pm 0.95$ & $-4.25 \pm 1.18$ & 0.03 \\
\hline Week 12 & $-5.22 \pm 0.91$ & $-4.68 \pm 1.06$ & 0.01 \\
\hline \multicolumn{4}{|c|}{$\begin{array}{l}\text { Patients with complete dryness, } \\
\text { n (\%) }\end{array}$} \\
\hline Baseline & 0 & 0 & NS \\
\hline Week 4 & $13(27.66)$ & $5(11.36)$ & 0.03 \\
\hline Week 12 & $13(27.66)$ & $5(11.36)$ & 0.03 \\
\hline \multicolumn{4}{|c|}{ Voiding volume (ml), mean (s.d.) } \\
\hline Baseline & $202.55 \pm 48.67$ & $218.95 \pm 53.35$ & 0.13 \\
\hline Week 4 & $159.39 \pm 41.08$ & $140.16 \pm 48.79$ & 0.04 \\
\hline Week 12 & $159.72 \pm 39.11$ & $139.07 \pm 41.61$ & 0.02 \\
\hline \multicolumn{4}{|c|}{ I-QoL, mean (s.d.) } \\
\hline Baseline & $37.27 \pm 7.14$ & $36.12 \pm 5.88$ & 0.41 \\
\hline Week 4 & $24.97 \pm 9.32$ & $19.59 \pm 11.83$ & 0.02 \\
\hline Week 12 & $26.01 \pm 11.56$ & $18.75 \pm 15.18$ & 0.01 \\
\hline
\end{tabular}

Abbreviations: I-QoL, Incontinence-Specific-Quality-of-Life Instrument; voiding volume, voided volume by $\mathrm{CIC}$ plus spontaneous voids; NS, no significance.

aThese variables were assessed from the patients' 7-day bladder diary.

NDO. Specifically, we found (1) according to our trial that only $57.45 \%$ of patients with NDO observed involuntary detrusor contraction at week 12; (2) the patients in the experimental group showed significant reductions in duration of the first detrusor contraction; and (3) most importantly, the $P_{\text {detmax }}$ decreased more significantly of including rather than excluding the trigone to levels traditionally considered safe for the upper urinary tract when bladder trigone was included rather than excluded. In our study, there was some differences in the total intradetrusor injected dose and number of injected sites between the experimental group (160 U, 24 sites) and the control group (200 U, 30 sites). However, Schurch et al. ${ }^{7}$ compared $300 \mathrm{U}$ (30 sites) and $200 \mathrm{U}$ (20 sites) BTX-A intradetrusor injections for NDO and found no significant differences in the safety and efficacy for the two different doses and sites. In addition, another study comparing $100 \mathrm{U}$ vs $150 \mathrm{U}$ of BTX-A in patients with idiopathic $\mathrm{DO}$ and also found that the clinical effect was equivalent in terms of symptom reduction and quality of life improvement. ${ }^{18}$ Moreover, the bladder trigone muscles are sensitive to minute pressure changes and have an important role in initiating involuntary detrusor contractions, which spread throughout the bladder muscles. ${ }^{9}$ Hence, trigonal denervation may help decrease such involuntary contractions, and thus we did not increase the intradetrusor injections dose in the experiment group.

Another important aims in the treatment of NDO is to improve the patient's QoL. ${ }^{17}$ The improvements in urodynamic outcomes also transfer into the increases in scores of I-QoL in both groups. Significant benefits were evident by week 12 . However, the mean change of I-QoL in the experiment group was substantially higher compared with that in the control group at week 12 (26.01 vs 18.75 , $P=0.01)$. The larger improvement in I-QoL in the experimental 
group may be related to the following changes: (1) the proportional reduction of daily urinary incontinence episodes was significantly larger with BTX-A intradetrusor plus intratrigonal injections compared with those excluding the trigone (71.95 vs $68.50 \%$, $P=0.02$ ); (2) the patients in the experimental group showed greater improvement in voiding volume compared with those in the control group (159.72 vs $139.07 \mathrm{ml}, P=0.02$ ); and (3) most importantly, 13 patients with BTX-A intradetrusor plus intratrigonal injections developed complete dryness postoperatively, and their I-QoL was very high. Thus, these patients are less likely to worry about the disturbance from urinary incontinence, which affects their physical activities, social relationships and feelings.

No patients developed systemic or significant adverse events of treatment in this trial. Similar safe outcomes have also been demonstrated by previous studies at $1.5-3$ months. ${ }^{10-15}$

A limitation of this study is that the number of patients was relatively fewer. Therefore, further studies are warranted.

\section{CONCLUSIONS}

Our results have demonstrated that BTX-A intradetrusor plus intratrigonal injections are more effective compared with those excluding the trigone for NDO of SCI patients. Intratrigonal injections do not induce VUR at 12 weeks postinjection.

\section{DATA ARCHIVING}

There were no data to deposit.

\section{CONFLICT OF INTEREST}

The authors declare no conflict of interest.

\section{ACKNOWLEDGEMENTS}

This study was supported by Medical Scientific Research Foundation of Guangdong Province, China (grant number A2013477).

1 Abrams P, Cardozo L, Fall M, Griffiths D, Rosier P, Ulmsten U et al. The standardisation of terminology of lower urinary tract function: Report from the Standardisation Sub-committee of the International Continence Society. Neurourol Urodyn 2002; 21 : 167-178

2 Schäfer W, Abrams P, Liao L, Mattiasson A, Pesce F, Spangberg A et al. International Continence Society. Good urodynamic practices: uroflowmetry, filling cystometry, and pressure-flow Studies. Neurourol Urodyn 2002; 21: 261-274.
3 Hagen EM, Eide GE, Rekand T, Gilhus NE, Gronning M. Traumatic spinal cord injury and concomitant brain injury: a cohort study. Acta Neurol Scand Supp/ 2010; 190: 51-57.

4 Denys P, Corcos J, Everaert K, Chartier-Kastler E, Fowler C, Kalsi V et al. Improving the global management of the neurogenic bladder patient. Part I. The complexity of patients. Curr Med Res Opin 2006; 22: 359-365.

5 Chapple C, Patel A. Botulinum toxin: new mechanisms, new therapeutic directions? Eur Urol 2006; 49: 606-608.

6 Hadiji N, Previnaire JG, Benbouzid R, Robain G, Leblond C, Mieusset R et al. Are oxybutynin and trospium efficacious in the treatment of detrusor overactivity in spinal cord injury patients? Spinal Cord 2014; 52: 701-705.

7 Schurch B, Stöhrer M, Kramer G, Schmid DM, Gaul G, Hauri D. Botulinum-A toxin for treating detrusor hyperreflexia in spinal cord injured patients: a new alternative to anticholinergic drugs? Preliminary results. J Urol 2000; 164: 692-697.

8 Andersson KE. Bladder activation: afferent mechanism. Urology 2002; 59: 43-50.

9 Klein LA. Urge incontinence can be a disease of bladder sensors. J Urol 1988; 139: 1010-1014.

10 Karsenty G, Elzayat E, Delapparent T, St-Denis B, Lemieux MC, Corcos J. Botulinum toxin type a injections into the trigone to treat idiopathic overactive bladder do not induce vesicoureteral reflux. J Uro/ 2007; 177: 1011-1014.

11 Citeri M, Spinelli M, Zanollo L, Scroppo F, Macrellino E, Redaelli T et al. Botulinum toxin into the trigone in neurogenic overactive bladder non-responder to detrusor injection. Eur Urol Supp/ 2008; 7: 213.

12 Pinto R, Lopes T, Frias B, Silva JA, Silva CM, Cruz C et al. Trigonal injection of botulinum toxin $A$ in patients with refractory bladder pain syndrome/interstitial cystitis. Eur Urol 2010; 58: 360-365.

13 Abdel-Meguid TA. Botulinum toxin-A injections into neurogenic overactive bladder to include or exclude the trigone? A prospective, randomized, controlled trial. J Urol 2010; 184: 2423-2428.

$14 \mathrm{Kuo} \mathrm{HC}$. Bladder base/trigone injection is safe and as effective as bladder body injection of onabotulinumtoxinA for idiopathic detrusor overactivity refractory to antimuscarinics. Neurourol Urodyn 2011; 30: 1242-1248.

15 Manecksha RP, Cullen IM, Ahmad S, McNeill G, Flynn R, McDermott TE et al. Prospective randomised controlled trial comparing trigone-sparing versus trigone-including intradetrusor injection of abobotulinumtoxin A for refractory idiopathic detrusor overactivity. Eur Urol 2012; 61: 928-935.

16 Patrick DL, Martin ML, Bushnell DM, Yalcin I, Wagner TH, Buesching DP. Quality of life of women with urinary incontinence: further development of the incontinence quality of life instrument (I-QOL). Urology 1999; 53: 71-76.

17 Stöhrer M, Blok B, Castro-Diaz D, Chartier-Kastler E, Del Popolo G, Kramer G et al. EAU guidelines on neurogenic lower urinary tract dysfunction [J]. Eur Urol 2009; 56: 81-88.

18 Cohen BL, Barboglio P, Rodriguez D, Gousse AE. Preliminary results of a dose-finding study for botulinum toxin-A in patients with idiopathic overactive bladder: 100 versus 150 units. Neurourol Urodyn 2009; 28: 205-208.

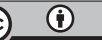

This work is licensed under a Creative Commons Attribution 4.0 International License. The images or other third party material in this article are included in the article's Creative Commons license, unless indicated otherwise in the credit line; if the material is not included under the Creative Commons license, users will need to obtain permission from the license holder to reproduce the material. To view a copy of this license, visit http:// creativecommons.org/licenses/by/4.0/ 